\title{
Exploring the Student Experience of the Final Year of a Professionally- Oriented Undergraduate Degree in Education Studies
}

\author{
Julie Uí Choistealbha, Roisin Donnelly, Marian Fitzmaurice \\ Marino Institute of Education, Ireland
}

\begin{abstract}
Within Higher Education there is growing expectations that graduates will enjoy smooth transitions into practice or further study and thus it is important to understand how higher education students' experiences in university should be best organised and integrated to realise these purposes. This qualitative research study investigated the impact of the curriculum design of the final year on student experience, engagement and progression routes post-graduation in a new four year professionally-orientated degree for students in a BSc in Education Studies in an Irish education institution. This study involved 26 lecturers and 25 recent graduates from the programme. Students were required to undertake a final year (capstone project) dissertation and an internship (involving the development of an ePortfolio to demonstrate and reflect on their journey of learning and to make connections with learning across the final year). Data was collected by means of an online student survey, followed by a focus group interview with self-selecting student participants as well a focus group interview with the programme development team. The focus of this work is on presenting the findings in terms of student experience of the balance between the internship and the dissertation as a preparation for their professional pathway; it also explores the lecturer experience as curriculum designers and facilitators. The study is underpinned by an exploration of enquiry-based learning, curriculum design, the capstone project and education studies as a discipline. Ultimately the intention of the research team is to improve the curriculum design process and outcome for the programme, and to contribute to the knowledge base on the highlights and challenges of designing and delivering professionally-orientated degrees into the future.
\end{abstract}

\section{Introduction}

This study is based on the final year of the BSc Education Studies Programme, a non-professional degree involving 26 lecturers and 25 recent graduates from the programme in Marino Institute of Education (MIE). The focus of this paper is on the student experience of the balance on an internship (work placement) and their research

dissertation, and the lecturer experience as curriculum designers and facilitators on this first full iteration of the programme. It includes an exploration of support for the 'world of work' for these students. Exploring the concept of a connected curriculum also played a valuable role in this study. The programme team are aiming to ensure that all MIE final year students are able to learn through participating in research, enquiry and the world of work at all levels of their programme of study. Figure 1 shows the curriculum components explored in this study which is focused on the final year of the programme.

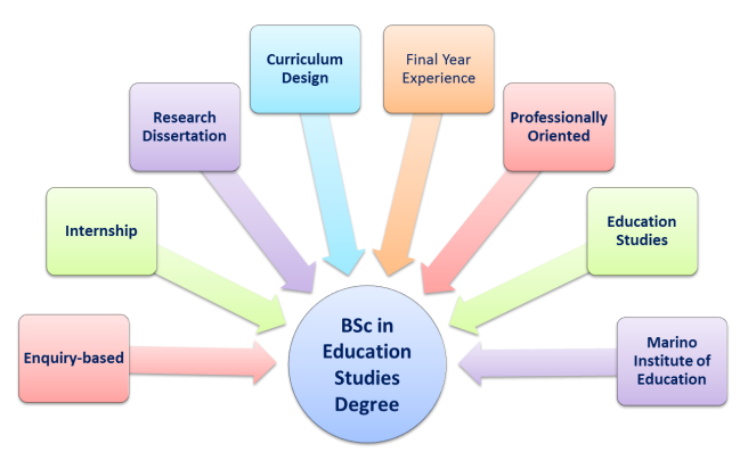

Figure 1. Final Year of BSc in Education Studies

\section{Context of the Professionally Oriented Programme in Education Studies}

Education Studies, if defined as philosophy, history, curriculum studies, sociology and psychology, can be considered as a building block of teacher education programmes [1]. In a national setting where the majority of education-related, higher education degree programmes lead to teacher accreditation and have a focus on a particular sector of education; early years, primary, post primary, further or higher education this definition is applicable.

However, within the literature on education studies, it has a broader definition: [2] separate a career in teaching from 'newer education 
professions' (p.1). Themes emerge in their study on the role of globalisation, market forces, cultural and ethnic dominance, change in society, lifelong learning, citizenship, and inclusion. [3] (p.3) define it as "a process as opposed to a subject area". Whereas [4] argues that the new education studies is a subject in its own right, but makes the case that it is not linked to initial teacher education. These 'newer' definitions of education studies are more applicable to this current study.

This research arose from an intention on behalf of the programme team to evaluate the student and lecturer experience once the first full iteration of the programme took place. The research was set within the context of our professional practice at Marino Institute of Education, where the three researchers work on the programme team of the BSc in Education Studies. The Education Studies programme commenced in September 2011 and was designed to serve the needs of those students who were interested in the broad field of education and not specifically focused on teacher accreditation. A professional degree is considered as a degree which focuses on a specific profession i.e. law, medicine, dentistry whereas a nonprofessional degree is more liberal in nature i.e. arts, humanities and basic sciences [5]. The Education Studies programme does not lead to teacher accreditation and focuses on the broad field of education through the lenses of ethics and social justice, lifelong learning, culture and policy. Although it is as such considered a nonprofessional degree it could be argued that it is professionally orientated within the education sector.

The 240 ECTS programme commences with a focus on adult education in first year, adolescent education in second year and childhood education in third year. Each of these three years follow a two 15 ECTS and six 5 ECTS module structure. The final year of the programme is devoted to an Internship experience, involving the development of an ePortfolio to demonstrate and reflect on their journey of learning and to make connections with learning across the final year (30 ECTS) and research dissertation (30 ECTS).

Set against this backdrop of a very different final year modular structure, a qualitative research study was initiated that would run over two academic semesters to investigate the impact of this programme design on the student experience and the pathways chosen by students post-graduation. This research approach would provide feedback to the programme team as how best to support future curriculum design and programme development.

Key for investigation were the supports available to students for completion of both the internship and the dissertation This study aimed to explore and establish if processes implemented to support students in developing the 'world of work' skills as well as their research capacity were helpful, and also to identify useful ways of supporting the development of the final year with future cohorts of students. The rationale for having supports on reflective writing and undertaking a research proposal were to enhance the students' reflective practice, and be incremental in order to get students to transform from descriptive narratives toward critical reflections. We believed that peer-learning and support between students should be built in and encouraged, with a community of final year students solving problems and addressing work-based learning and research issues together. Based on the components of the professionally-oriented degree at the heart of this study, Figure 2 illustrates the areas of the literature that were pertinent for exploration, and these are discussed in the subsequent section of the paper.

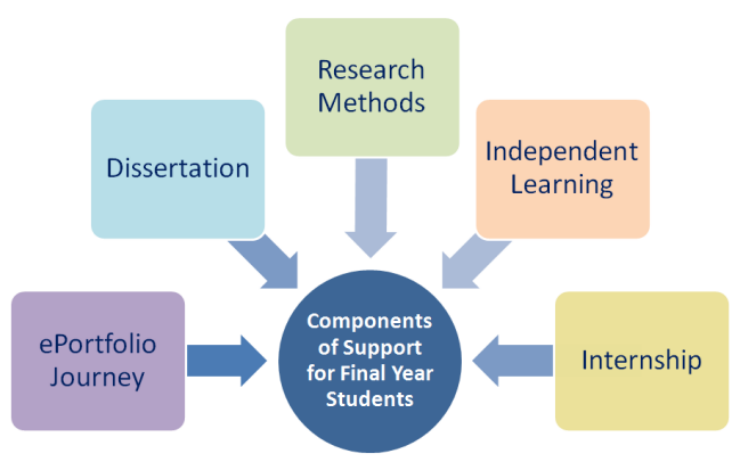

Figure 2. Areas of the Curriculum Selected for Connection

\section{Literature Review}

Various authors refer to three main stages of development of a university teacher [6], [7], where initially as teachers we are concerned if students will like us and if we know enough; we then examine our teaching skills; finally we wonder how the students are learning and if they are making learning connections that will help them towards life-long learning. In this study, we were interested in improving our practice to move from a teachercentred focus towards a student-centred facilitation of learning [8]. We wanted to ask ourselves how we could improve what we were doing as designers of the programme [9] and develop a practice of reflective action towards constant improvement in the final year learning environment that we facilitated. Indeed we wanted to 'be professional' by engaging in critical and constructive analysis of our professional practice, identity and values [10].

On embarking on our teaching role on the final year of the programme, we were aware of many theories and paradigms of learning and teaching [11]. We were very much aware of acknowledging 
the importance of our collective values as educators as a programme team, as the outcome of a previous study on curriculum design had indicated [12]. We could acknowledge and discern what was of value to ourselves and became aware that we valued our role as educators as being of service to others, and being in a position in the world to enable other people to reach their highest potential. We value students as individuals with their own distinct experiences, views and knowledge, and this is especially true on a professionally-orientated degree such as this. We also value that each student should be able to express their own individuality in the learning environment, and believe that is our role to respect student individuality and independence, but at the same time to guide them in achieving the learning outcomes that they seek to accomplish.

We wanted to investigate if we were constructively aligning [13] the learning activities facilitated with students with the learning outcomes that they needed to achieve. Also we wanted to ensure that we were living our values [14], which would strengthen and deepen our knowledge, enable us to work creatively with the final year students and ultimately empower and prepare others with a disposition for lifelong learning [10]. We consider ourselves as facilitators - a medium, rather than the medium through which learning is enabled. We wanted to provide the final year students with an environment that encouraged confidence and equipped them with tools so that they could become critical learners through active engagement and a student centred, enquiry-based focus [8].

\subsection{The Connected Curriculum}

The study was informed by the current work by [15] on the connected curriculum with its focus on learning though research and enquiry. Key to this approach is designing programmes to provide students with opportunities to connect at a number of levels. Of particular relevance to this current study were having a through line of research activity built into the programme, students making connections across subjects and out to the world of work, connecting their academic learning to their workplace learning, and connecting with each other in the final year of the programme. Also of relevance to the study was the work of [16], especially on the internship component of the final year of the programme, offering as its focus the three kinds of work in the future: solving unstructured problems, working with new information and carrying out non-routine tasks.

\subsection{Enquiry-based Learning}

Recommendations from literature on enquirybased learning (EBL) in classrooms [17] advocate a trusting, safe environment that encourages divergent thinking and risk-taking. As educators, we would need to be open to taking risks on enquiry-based approaches while seeking to give students feelings of security. As facilitators, and in working towards this aim, we would have the valuable opportunity to demonstrate integrity, acknowledge our values and make explicit a commitment to exploring and reflecting on our professional practice [10], [18].

While this study would work towards the aim of improving the student learning experience of the final year of the programme and prepare them for the 'world of work', it would pay particular attention to nurturing an enquiry-based approach with students in the learning environment in which they engaged in order that critical thinking practices could be evident in the work placement and the research dissertation. In order to set about fostering enquiry, literature was explored that would help deepen our knowledge of EBL and help us to come up with a definable scope of an enquirybased curriculum that could be fostered and worked towards during the period of this study.

Enquiry based learning in primary schools has been popular for the last number of years as a means to provide an opportunity for children to act as co-constructors of their curriculum. This approach to curriculum is used so that children are encouraged to research, investigate and problemsolve to inform their learning. It is oft cited as encouraging children to take ownership of their learning and become engaged, independent and motivated. It makes sense then that the curriculum being studied by the future educators in Ireland also uses this approach in its programmes. This learnercentred approach emphasises higher order thinking skills, and may take several forms, including analysis, problem solving, discovery and creative activities, both in the classroom and the community. Most importantly, in enquiry learning students are responsible for processing the data they are working with in order to reach their own conclusions.

Within the context of contemporary teacher education, [19] argue that programmes should seek to develop educators who can enquire systematically and critically into their educational practices, and call for more enquiry-based teacher education. A study by [20] on first-year undergraduates on degree programmes in the arts, humanities and social sciences presented a conceptual framework for the practice of enquirybased learning.

Over the past decade, there have been a number of respected guidelines developed to inform 
programme teams about designing undergraduate curricula to be enquiry-based. The [21] guide to an enquiry-based curriculum advocates four main characteristics: a clear, but open, starting point; resources to support learning; peer support; and facilitation.

The role of independent enquiry manifests itself in the final year dissertation in undergraduate education studies programmes.

\subsection{Evaluating Students' Learning Experiences from a Learning Ecology Perspective}

As evaluating the student learning experience of final year was a key element of the study, the work of [22] on a conceptual tool (Figure 3) was helpful for thinking about what areas of the student learning experience in final year we needed to better understand. The learning ecology dimension relevant for our current study includes goals and intended outcomes, knowledge and skill content, processes, spaces, relationships, resources including tools, technologies and mediating artefacts and recognition of achievement.

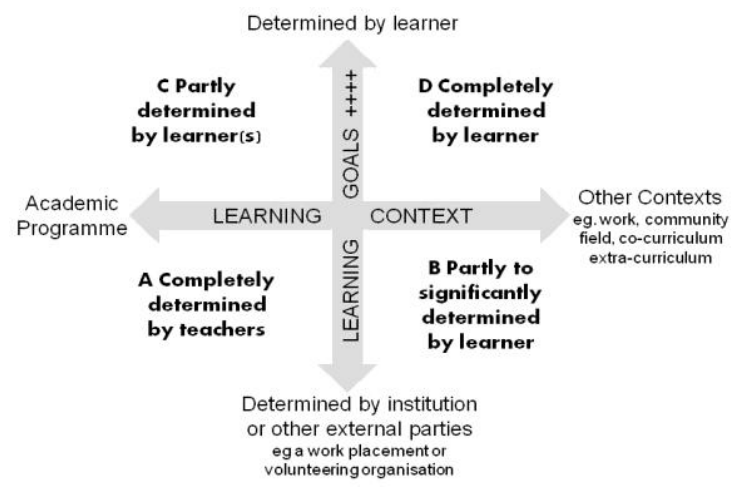

Figure 3. Learning ecology influencing how we evaluated the student learning experience

In his well-known work, [22] argues that curriculum designers could evaluate the potential of a students' curriculum to support their own learning ecologies using a simple conceptual aid such as that shown in Figure 3.The contexts or environments for learning explore whether the contexts are formally constituted and structured within an academic programme or whether they are more informal semi- or unstructured opportunities for learning and development connected to or outside the academic programme. It is also important to consider whether the institution or the learner determines the what and why, the how, where and the when of learning, and ultimately determines what counts as learning. The key question is who determines the goals and purposes, knowledge and skill content, processes, resources, tools and technologies outcomes and achievements.
Principles of good practice at undergraduate level by [23] were also useful to bear in mind for the context of the study, especially the programme design team perspective. [22] Also is a proponent of these. Having an active dimension to learning, involving the student in 'doing' as a cognitive activity and 'doing' as a practical activity in which cognitive activity is embedded. Cumulative learning involves awareness of what a student already knows as this plays a large part in them being able to make sense of and meaning from new knowledge or experience, and is a major factor in determining the efficacy of a particular learning event. Designing purposeful, relevant and goaloriented instruction where there is a purpose and direction, understood by the student is key; clear goals are needed if learning is to be effective. Personal learning is experienced by the student alone, where they interpret and construct knowledge and meaning in a unique way; while this is important, it needs to be borne in mind that learning is often within a social context. Situated and contextual learning is vital, where the social and physical context in which cognition (learning) takes place is influential in shaping understanding, meaning, process and outcomes. Cognition can be distributed across individuals and artefacts. Selfregulated learning should feature at undergraduate level - involving the student's own understanding and decisions about what they need to do in order to achieve something and by their awareness of their own learning informed by reflection on their experience. Underlying, self-directed and selfmanaged learning is a sense of purpose and selfefficacy - the belief a person has about their ability to succeed in a particular situation.

\section{Research Study}

The aim of the study was to investigate the impact on student experience, engagement and progression of the curriculum design of the final year of a professionally-orientated degree programme in education studies, as illustrated in Figure 4 . The qualitative study began in November 2015 with the design of an online survey for the 25 graduates of the programme using the Survey Monkey tool. This was implemented in mid January 2016, and 14 graduates responded. The follow-up focus group interview with 5 of these respondents is scheduled for mid May 2016. The dual dimension of the study was an investigation of staff perspectives of the connected curriculum; a focus group interview with the full programme team of 8 lecturers was held in April 2016.

\section{Findings}

The theme of professional pathways was explored from two perspectives: that of the impact 
of the internship, followed by the impact of the research dissertation, as illustrated in Figures 5 and 6.

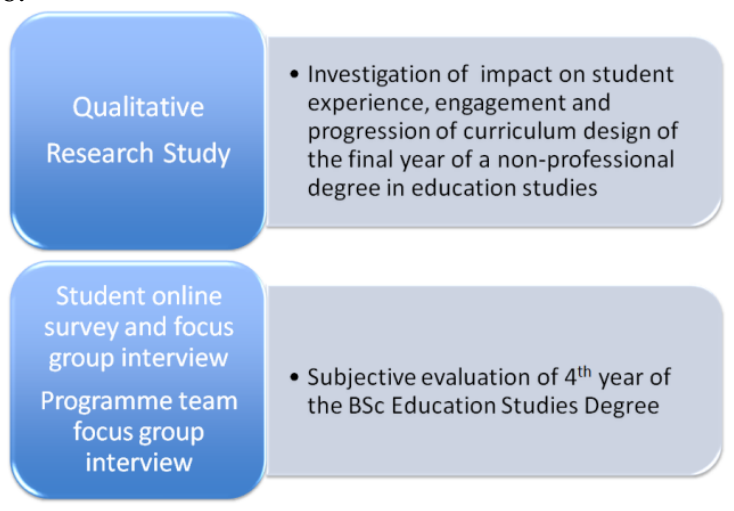

Figure 4. Overview of the Research Design

\subsection{Impact of Internship}

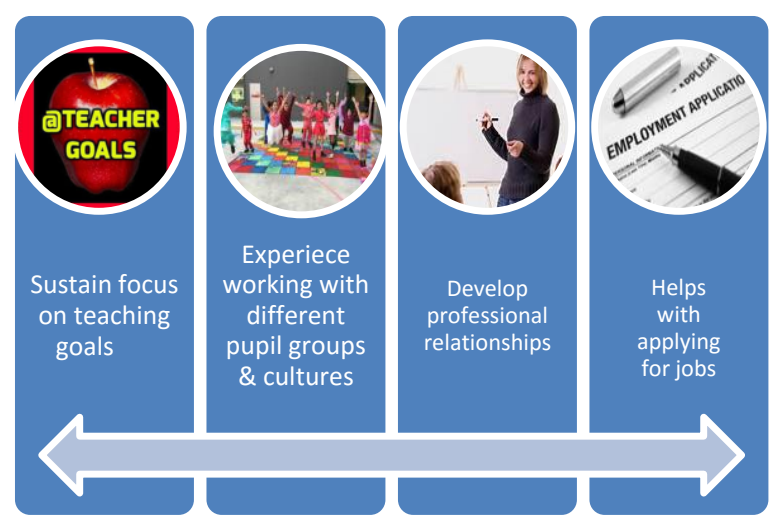

Figure 5. Impact of Internship on Professional Pathways

The internship impacted students on a variety of levels [22], [23]. Their learning from the internship was active as a result of the goal orientated projects; it was cumulative as it called on the student to look back on the course content since first year and at the same time to look forward to their life after graduation; it was purposeful in that it provided clarity of future pathways; personal in terms of the level of individual growth and development; situated in specific learning environments that called on professional relationships to be developed with staff and/or students and it was self-regulated through the use of the ePortfolio as a means of reflection.

\subsection{Value of Research Dissertation}

Students highlighted a number of areas of value in undertaking the dissertation process. Looking at impact on their satisfaction in researching a topic of personal interest, students believed it enabled them to show passion in education topics, develop research skills, help them understand the value of research, and develop education specialisms such as special educational needs and literacy. This echoes studies by [24] which would concur, arguing that completing the dissertation process shows commitment, perseverance, self motivation, independent study, initiative and critical thinking all essential elements to establishing competency as a viable candidate for any graduate position, and develops a sense of freedom, independence, achievement and pride that may be lacking in other areas of undergraduate study. There are future opportunities in balancing the internship and dissertation for students, especially by gearing their research topic towards the professional pathway they are interested in taking up in the future. Interestingly, when thinking about the value of a dissertation for their professional futures [25], the direct impact on employability did not arise.
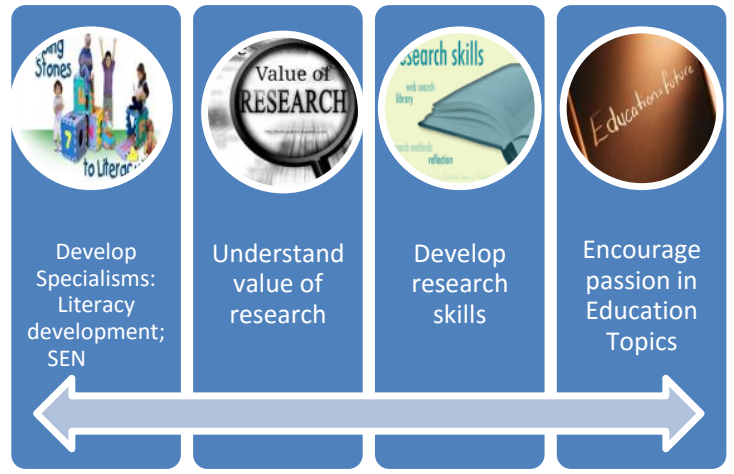

Figure 6. Impact of Research Dissertation on Professional Pathways

\subsection{Challenges facing Students/Graduates}

In terms of balancing the two key components of the curriculum in the final year of the programme, a number of challenges emerged from the student perspective. These are challenges highlighted by students about their experience in final year. There were opinions expressed about securing the internship initially as stressful, apprehensive, overwhelming and intense. Equally, the research dissertation was perceived as challenging, especially the process of conducting interviews, finding an organisation to conduct the interviews with, undertaking academic writing, and wanting more time on the dissertation along with further supervisor meetings.

It is also important to explore the challenges facing the programme graduates. As part of the study, we had asked where they were now in order to better understand the choices that they made post-graduation. The choices made by students post-graduation adhere to the notion of the Education Studies degree being professionallyorientated as opposed to professional or nonprofessional [5]. The data showed that there was no one clear direction taken by students post- 
graduation with a spread of pathways including further study in both education-related and noneducation related fields as well as employment in both education-related and non-education related fields. The students indicated that the final year experience heightened their awareness of the range of educational organisations in Ireland and further afield, the varying postgraduate qualifications needed to work in these organisations and the importance of culture and environment when choosing where to work or study. Students indicated that these variables were at times in contrast to what they had expected to be a linear journey to the world of education, in particular those who had initially intended on becoming primary school teachers.

\subsection{Perceived Benefits of a Connected Curriculum}

Taking into consideration how the final year of the programme was structured to allow a connection to the word of work via both the internship and the research dissertation, a range of benefits were identified by the students. These included that it was enjoyable, interesting, rewarding, practical, linked to link to further study and/or world of work, was career focused and career shaping, allowed for the exchange of ideas as well as enhancing self-esteem and personal competences. The lectures which ran in conjunction with the practical elements of the year (internship and capstone project) supported students understanding and experience of the connected curriculum provided [15], [16].

Students also identified a range of skills that they developed in the final year of the programme. These included communication, problem-solving, teamwork, leadership, organisation, time management; motivation, the ability to multitask, take risk and teach, interpersonal skills, confidence, independence, ideas generation, presentation skills and the ability to conduct and analyse research whilst putting theory to practice. This level and depth of skill development was facilitated by the learning environment [17] which students described as supported, guided, challenging, exciting and reassuring.

\subsection{The Programme Team Perspective}

The programme team perspective was interesting to compare to that of the students. Collaboration by team members was considered to be key in design and delivery of modules across the four years of the degree. In relation to the Capstone Project in the final year, it was felt by the programme team that it was well-grounded in research across the academic year, and there was a strong connection between the theory and the practice in education studies. Specifically in year 4, the research and internship modules worked, but there was an indication that there was a need for a new module to be developed to connect the learning from the preceding years of study. This could address the issue of year 4 being somewhat isolated from the rest of the programme. There was also mention made of the programme pillars: ethics and social justice, lifelong learning, culture and policy and specifically how these could be used to orientate choices made by students regarding research topics and internship locations, thus providing a link to the first three years of the programme.

Looking specifically at how the programme impacted the students, there was also a collective belief from the programme team that the curriculum design of the programme supported the students to become more independent learners. This reflects findings of a study by [26] who reported that the dissertation still has currency today, and the lecturers believed that it gave students the ability to reach a level whereby they become autonomous learners.

All on the team observed a change in the students after the internship, evidenced by their development of workplace skills and that they could talk the language of recruitment. It was perceived by the team that it would be a disservice to the students if they did not have a significant piece of work experience as part of the degree programme. Thinking ahead to the next iteration of the programme, it was agreed that there was a need for more of a focus on innovation, although it was acknowledged that in this current year, the ePortfolio had greatly improved.

\section{Conclusions}

This study was reporting on the impact on the student experience and engagement of the curriculum design of the final year of a professionally-oriented degree in education studies. As it is currently only the mid-point of the research study, a number of reflections were useful to acknowledge at this stage:

How well did the final year prepare students for the path chosen by each on completion of the degree? Students were in the main very positive about the impact of the programme on preparing them for their chosen professional pathway. Balancing the internship and the dissertation to provide a holistic learning experience appears to be working so that the students can fulfil their potential through undertaking their final year more closely aligned to their needs and aspirations.

What were they key variables in the programme design and implementation process for the final year from the staff perspective? It will be important for the programme team to bear in mind that the 
role of dissertation as the capstone of Bachelor degrees is likely to be of growing significance as a key way of delivering programme-learning outcomes and research-informed teaching [27].

After synthesising different perspectives from students and staff on the curriculum design of the final year of the BSc in Education Studies, a number of areas emerged for the programme team to concentrate on in order to improve the final year student experience. Facilitated workshops are being designed to provide students with opportunities to synthesise the learning from the first three years with a view to providing students with a platform to bring cohesion to their learning over the four years, culminating in their chosen pathway postgraduation. These will form part of the first term experience for students in the final year. The programme team are putting into place a scaffolded approach to the use of the ePortfolio from year one in order that students can construct more innovative portfolios. Given the varying paths chosen by students post-graduation, a more formalised support structure for students will be implemented in order for them to have a greater understanding of the range of choices available to them postgraduation.

\section{Future Research}

Given the infancy of the Education Studies programme, there is scope to engage in future research on the pathways chosen by students within the first five years of graduation. This would explore if the hope of the programme designers to foster life-long learning skills was realised.

Further research on the intersection of skills between the research project and internship experience is necessary to see if students view skills as transferrable or isolated to specific assessment tasks.

There is also potential to explore how the four pillars of the education studies programme (ethics and social justice, lifelong learning, culture and policy) inform the choices made by students in the final year and subsequent pathways postgraduation.

This research study focused on the final year programme design team but future research could incorporate the perceptions of the wider Education Studies and even wider Institute staff on the Education Studies degree as a new programme in an Institution with a long history of teacher accreditation.

\section{References}

[1] Drudy, S., (2010). Foreward in Education Studies in Ireland, edited by Brendan Walsh, ix-x. Dublin: Gill \& MacMillan.
[2] Sharp, J., Ward, S., \& Hankin, L., (2010). Education Studies: An issues-based approach. Exeter: Learning Matters.

[3] Murphy, L., Mufti, E., \& Kassem, D., (2009). Education Studies: An Introduction. Berkshire: McGraw Hill.

[4] Ward, S. (Ed.) (2008). A Student's Guide to Education Studies. Oxon: Routledge.

[5] Arora, M., (2015). A comparative study between professional and non-professional course students: Social Adaptability. International Journal of Humanities \& Social Science Studies, 1(5), 26-31.

[6] Norton, L., (2009). Action Research in Teaching and Learning: A Practical Guide to Conducting Pedagogical Research in Universities. London: Routledge.

[7] Conway, P., \& Clark, C., (2003). The journey inward and outward: a re- examination of Fuller's concernsbased model of teacher development. Teaching and Teacher Education, 19, 465-482.

[8] O'Neill, G., \& McMahon, T., (2005). Student Centred Learning: What does it mean for Students and Lecturers? In G. O'Neill, B. McMullin, \& S. Moore (Eds.), Emerging Issues in the Practice of University Teaching and Learning (pp. 27-36). Dublin: AISHE.

[9] Whitehead, J., \& McNiff, J., (2010). You and Your Action Research Project ( ${ }^{\text {rd }}$ Edition). New York: RoutledgeFalmer.

[10] Nixon, J., (2008). Towards the Virtuous University: The Moral Bases of Academic Practice. New York: Routledge.

[11] Jordan, A., Carlile, O., \& Stack, A., (2008). Approaches to Learning: A Guide for Educators. Maidenhead: Open University Press.

[12] O'Neill, G., Donnelly, R., \& Fitzmaurice, M., (2014). Supporting Programme Teams to Develop Sequencing in Higher Education Curricula. International Journal of Academic Development, 19(4).

[13] Biggs, J., \& Tang, C., (2007). Teaching for Quality Learning at University ( ${ }^{\text {rd }}$ Edition). Maidenhead: Open University Press.

[14] Breslow, L., (2010). An educational developer's autobiography. In S. Boon, B. Matthew, \& L. Sheward, Eds.), Creating a Profession - Building careers in educational development (pp. 33-35). Staff and Educational Development Association Special 27.

[15] Fung, D., (2015). UCL Connected Curriculum: A Distinctive Approach to Research-based Education. London UK: University College London Centre for Advancing Learning and Teaching. Accessed 18 April, 2016. 
[16] Bass, R., (2014). Designing Undergraduate Curricula for 2030: A catalyst for change. Georgetown University.

[17] Jenkins, A. \& Healey, M., (2012). Research-led or research-based undergraduate curricula. In University teaching in focus: A learning centred-approach, edited by Lynne Hunt and Denise Chalmers, 128-177. Camberwell, Victoria: Acer.

[18] Palmer, P., (1998). The Courage to Teach. San Francisco: Jossey-Bass.

[19] Reid, A., \& O’Donoghue, M., (2004). Revisiting enquiry-based teacher education in neo-liberal times. Teaching and Teacher Education, 20(6), 559-570.

[20] Levy, P., \& Petrulis, R., (2012). How do first-year university students experience inquiry and research, and what are the implications for the practice of inquirybased learning? Studies in Higher Education, 37(1), 85101.

[21] Kahn, P., \& O'Rourke, K., (2004). Guide to Curriculum Design: Enquiry-Based Learning. HEA Academy. http://78.158.56.101/archive/palatine/files/ 1009.pdf

[22] Jackson, N. J., (2011). An imaginative lifewide curriculum. In N.J. Jackson (Ed.) Learning for a Complex World: A lifewide concept of learning, education and personal development (pp. 100-121). Authorhouse.

[23] Chickering, A.W., \& Gamson, Z.F., (1987). Seven principles for good practice in undergraduate education. American Association of Higher Education Bulletin, 39(7), 3-7.

[24] Todd M., Smith K., \& Bannister P., (2006). Supervising a social science undergraduate dissertation: staff experiences and perceptions. Teaching in Higher Education, 11(2) 161-173.

[25] Minnighan, N., (2010). Graduate view: Why a dissertation can boost your employability. The Guardian. http://www.theguardian.com/careers/graduate-view-whya-dissertation-can-boost-your-employability

[26] Feather, D., Anchor, J.R., \& Cowton, C.J., (2011). The Value of the Undergraduate Dissertation: Perceptions of Supervisors. In Paper presentations of the 2010 University of Huddersfield Annual Learning and Teaching Conference (pp. 41-56). University of Huddersfield.

[27] Healey, M., Lannin, L., Stibbe, A., \& Derounian, J., (2013). Developing and enhancing undergraduate finalyear projects and dissertations. University of Gloucestershire: HEA Academy. 